\title{
A Novel Prognostic Risk Score Based on Ferroptosis-related LncRNAs Predicting Ovarian Cancer Patient Survival
}

\section{Keyu Chen}

Zhejiang Chinese Medical University

\section{Xiaohong Li}

Zhejiang Chinese Medical University

Caixia Qi ( $\sim$ ren000819@163.com)

Zhejiang Chinese Medical University

\section{Research Article}

Keywords: ovarian cancer, ferroptosis, IncRNA, prognostic features

Posted Date: December 28th, 2021

DOI: https://doi.org/10.21203/rs.3.rs-1188209/v1

License: (c) (i) This work is licensed under a Creative Commons Attribution 4.0 International License.

Read Full License 


\section{Abstract}

Background: Long non-coding RNAs (IncRNAs) are thought to be associated with several processes during cancer development and have been shown to be involved in the regulation of ferroptosis. Ovarian cancer is highly malignant tumour with a poor prognosis. The identification biomarkers with prognostic value in ovarian cancer may improve patient outcomes and can help to elucidate potential future therapeutic targets.

Results: We report differential expression of 187 ferroptosis-related IncRNAs in normal and ovarian cancer tissue. Using univariate and multivariable Cox regression analysis, we identified four IncRNAs that were strongly associated with prognosis. We constructed a prognostic risk score based on these four IncRNAs which was effectively able to distinguish between low- and high-risk OC patients based on survival time. Univariate and multivariable Cox regression analyses and time-related receiver operating characteristic curve analyses revealed that this risk score represented an independent prognostic factor in patients with ovarian cancer. For clinical implementation, we developed a nomogram based on the prognostic feature and patient age. Gene Ontology $(\mathrm{GO})$ analysis and Kyoto Encyclopedia of Genes and Genomes (KEGG) analysis revealed that the four ferroptosis-related IncRNAs were related to tumour immunity.

Conclusions: we identify four novel ferroptosis-related IncRNAs as predictors of ovarian cancer prognosis and potential future therapeutic targets for ovarian cancer.

\section{Background}

Ovarian cancer (OC) is the fifth most common cause of cancer mortality in women [1]. In 2021, there were 21,410 new diagnoses of $O C$ and 13,770 OC patients died from their disease in the US [2]. The prognosis of $\mathrm{OC}$ patients is heavily influenced by the stage at diagnosis [1]. Currently, the lack of effective screening tools and unspecific symptoms of early stage $\mathrm{OC}$ result in late diagnosis of a majority of patients, when metastases are already present [1,3]. The 5 -year survival rate of advanced OC is $29 \%$, and more than $80 \%$ of patients experience recurrence[3,4]. Despite significant developments in $\mathrm{OC}$ treatment options over the past two decades, overall survival (OS) rates have not improved drastically. Therefore, it is important to establish reliable prognostic features which may enable more accurate prognosis and could represent therapeutic targets in order to extend OS [5]. Certain IncRNAs have previously been shown to be associated with $\mathrm{OC}$ prognosis[6]. Due to the complex molecular mechanisms of tumours, polygenic models (incorportating several markers) tend to perform better at prognosis prediction than single genes.

IncRNAs are transcripts that are longer than 200 nucleotides which are not involved in protein translation.In recent years, IncRNAs have been reported to be involved in the proliferation and metastasis of cancer cells[7].A related study reported that LncRNA MIR4697HG may be responsible for slowing down the proliferation of OC cells through ERK and AKT signaling pathways[8].In addition, some specific 
IncRNAs have been reported to predict cancer progression, which means that IncRNAs can be used as prognostic biomarkers for cancer[9].

Ferroptosis is a type of regulated cell death (RCD) distinct from apoptosis. It is closely linked to cellular iron levels and can be regulated by a variety of genes [10]. Cells undergoing ferroptosis exhibit normal nuclei and intact membranes, but have a reduced mitochondrial volume, increased mitochondrial membrane density, and loss of mitochondrial cristae [11,12]. Ferroptosis is characterized by the accumulation of lipid metabolites and cellular iron and excessive generation of reactive oxygen species. In addition, ferroptosis has been reported to contribute to low activity of glutathione peroxidase 4 (GPX4) [13]. Over last decade, the involvement of iron toxicity has been demonstrated in various tumours, and is furthermore related to treatment efficacy of tumours, including $\mathrm{OC}$ [14]. There is now increasing evidence that the iron metabolism may be strongly associated with cell growth and metastasis in OC. For instance, Basuli et al. observed a decrease in Ferroportin (FPN) and an increase in Transferrin receptor protein 1 (TfR1) levels in OC tissues. The authors hypothesized that OC cells exhibit both an increased iron content and iron dependence, suggesting that $\mathrm{OC}$ cells may be sensitive to ferroptosis-inducing drugs [15].

Based on the above discoveries, we hypothesized that IncRNAs and ferroptosis may play a critical role in tumour development and treatment. As the involvement of IncRNAs and ferroptosis in OC has not yet been assessed in depth, further studies exploring the role of IncRNAs and ferroptosis in OC development are warranted. Current therapeutic options for $\mathrm{OC}$ include surgical resection and platinum-based chemotherapy [16]. To explore whether the expression of ferroptosis-related genes differs between normal and ovarian cancer tissues, we conducted an in-depth study using relevant data from the the Cancer Genome Atlas (TCGA) and Genotype-Tissue Expression (GTEx) databases. The predictive prognostic performance of these genes was further explored and prognostic features based on four ferroptosisrelated genes were developed. In conclusion, we successfully explore the expression of ferroptosis-related genes and constructed prognostic features with potential application to clinical treatment in this study.

\section{Methods}

\section{Data}

Gene expression data and individual clinical information of OC patients were derived from TCGA. Due to an absence of data on normal ovarian sample in the TCGA cohort, we have supplemented data from normal samples $(n=88)$ derived from GTEx. It is worth noting that the GTEx and TCGA databases are based on the same technology and platform. A list of ferroptosis-related genes $(n=259)$ (Supplementary Table 3) was obtained from the FerrDb [14].

\section{Screening and of ferroptosis-related IncRNAs}

RNA-seq data accessed from TCGA and GTEx were combined. Based on FerrDb, we identified ferroptosisrelated mRNAs. We used pearson correlation to further identify ferroptosis-related IncRNAs that met the following criteria: correlation coefficient $\left|R^{2}\right|>0.6, p<0.001$. 


\section{Identification of DEGs}

DEGs associated with iron toxicity were identified using the limma package, based on the following criteria: FDR $<0.05,|\log 2 F C|>1$. A heatmap reflecting expression levels of DEGs in tumour and normal samples was created using the $\mathrm{R}$ heatmap package.

\section{Construction and examination of prognostic features}

We randomly assigned 184 of the 364 OC patients with complete survival information from the TCGA cohort ( "entire dataset") to the "primary dataset". We did not observe significant differences in clinical characteristics (age and grading) between the primary dataset and the entire dataset. The prognostic value of ferroptosis-related IncRNAs in the primary dataset was assessed via univariate Cox regression and identified ferroptosis-related IncRNAs with a high correlation with the survival status $(p<0.1)$ as candidate genes. We then used multivariable Cox regression analysis to further explore the prognostic potential of candidate genes for prognostic features $(p<0.05)$. The prognostic score was calculated as follows:

Risk Score $=\left(a_{1} *\right.$ gene $\left._{1} \exp \right)+\left(a_{2} *\right.$ gene $\left._{2} \exp \right)+\cdots\left(a_{n} *\right.$ gene $\left._{n} \exp \right)$

We further subdivided patients in the primary dataset into a low-risk and high-risk subgroup by median prognostic features. We assessed the predictive performance of prognostic features on OS via receiver operating characteristic curves and Kaplan-Meier survival curves. The risk score for every patient in the entire dataset was calculated using the same formula as in the primary dataset to validate prognostic features. We then divided the "entire dataset" of patients into low- and high-risk subgroups based on the median risk score of the "primary dataset" and further validated the predictive performance using receiver operating characteristic curves and Kaplan-Meier curves.

\section{Construction of Nomogram based on prognostic features}

We performed univariate and multivariable COX regression analyses on the "entire dataset" and "primary dataset", respectively, to determine whether prognostic characteristics were independent prognostic factors. Nomograms based on data from the "entire dataset" was then created in order to predict the survival rates of $O C$ patients after 1,2 , and 3 years, with the calibration curves plotted to validate the predictive effect.

\section{Function enrichment analyses}

We identified mRNAs co-expressed with OS-related IncRNAs $\left(\left|R^{2}\right|>0.6, p<0.001\right)$ and subjected them to KEGG and $\mathrm{GO}$ analyses to assess molecular functions, cellular components, and major signalling pathways involved in OS-related IncRNAs. $p<0.05$ was considered statistically significant.

\section{Statistical analysis}


We used Student's t-test to identify DEGs, and Pearson correlation test to assess the co-expression of IncRNAs and mRNAs. The PERL programming language was used to process clinical and genetic data (version 5.30.2, http://www.perl.org). We used R software (version 4.1.0) for statistical analyses and all pvalues were two-tailed.

\section{Results}

\section{Identification of ferroptosis-related genes}

Combining RNA-seq data from TCGA and GTEx, we identified 19,555 mRNAs and 13,829 IncRNAs. We assessed 240 ferroptosis-related mRNAs and found 315 ferroptosis-related IncRNAs via correlation analysis $\left(\left|\mathrm{R}^{2}\right|>0.6, \mathrm{p}<0.001\right)$.

\section{Identification of differentially Expressed IncRNAs}

Comparing the expression of 315 ferroptosis-related IncRNAs in 379 OC tissues from TCGA and 88 normal tissue from GTEx, we identified 187 differentially expressed genes (DEGs) $(p<0.01)$, of which 48 were downregulated in OC while 139 were upregulated. Figure 1A shows a heatmap of expression levels of the abovementioned IncRNAs. A volcano plot in Figure 1B shows the differential expression of ferroptosis-related IncRNAs in normal and tumor sample.

\section{Identification of candidate IncRNAs associated with overall survival}

We next assessed the association of ferroptosis-associated IncRNAs with overall survival (OS). Fifteen patients were excluded from the TCGA dataset due to a lack of complete clinical data. Among the 364 remaining OC patients ("entire dataset"), we randomly assigned 184 patients to the "primary dataset"(Patient IDs in the primary dataset can be found in Supplementary Table 1), which did not exhibit significant differences in clinical data compared with the entire dataset (Table 1). We evaluated the prognostic performance of 187 ferroptosis-related DEGs by Kaplan-Meier analysis and univariate Cox regression analysis, resulting in the identification of 7 candidate IncRNAs closely associated with OS $(p<0.1)$ (Table 2). Figure 2A shows a forest plot of these 7 genes, three of exhibited a hazard ratio $(H R)>1$ and are therefore likely associated with a worse prognosis, while the remaining four IncRNAs had a $H R<1$. Kaplan-Meier curves of the 7 IncRNAs showed the same trend as the above results (Figure 2B-H).

Table 1. Comparison of clinical data for the primary and entire dataset 


\begin{tabular}{llll} 
Character & primary dataset & entire dataset & pvalue \\
\cline { 2 - 3 } & $\mathrm{n}=\mathbf{1 7 0}$ & $\mathrm{n}=339$ & \\
\hline Agelyear[ & & & 0.701 \\
\hline$\geq 65$ & $35.87 \%$ & $35.44 \%$ & \\
\hline$\square 65$ & $64.13 \%$ & $64.56 \%$ & \\
\hline Grade & & & 0.833 \\
\hline G1 & $0.54 \%$ & $0.27 \%$ & \\
\hline G2 & $10.87 \%$ & $11.54 \%$ & \\
\hline G3 & $87.50 \%$ & $87.64 \%$ & \\
\hline G4 & $1.09 \%$ & $0.55 \%$ & \\
\hline
\end{tabular}

Table 2. Univariate Cox results for IncRNAs based on the primary dataset

\begin{tabular}{lll} 
id & HR $(95 \% \mathrm{Cl})$ & pvalue \\
\hline AC138904.1 & $0.722(0.515-1.011)$ & 0.058 \\
\hline DNM30S & $1.105(1.005-1.214)$ & 0.039 \\
\hline USP30-AS1 & $0.842(0.718-0.987)$ & 0.034 \\
\hline FOXP4-AS1 & $0.780(0.614-0.991)$ & 0.042 \\
\hline AC020916.2 & $1.349(1.010-1.801)$ & 0.042 \\
\hline LINC01150 & $1.273(0.958-1.693)$ & 0.096 \\
\hline AC068870.2 & $0.874(0.749-1.020)$ & 0.088
\end{tabular}

\section{Prognosis feature construction and examination}

We used a stepwise multivariable Cox regression analysis to identify the optimal combination of OSrelated IncRNAs. The Akaike information criterion (AIC) was employed to prevent overfitting that it can not over-fitted. Finally, four OS-related IncRNAs (AC138904.1, DNM30S, USP30-AS1, and FOXP4-AS1) were selected from the multivariable Cox proportional hazards model (Table 3). A prognostic risk score based on the ferroptosis-related IncRNAs was created based on the following formula:

Risk Score $=-(0.326 \times$ AC138904.1exp $)+(0.100 \times$ DNM30Sexp $)-(0.172$

$$
\times \text { USP30 - AS1exp })-(0.248 \times \text { FOXP4 - AS1exp })
$$

We next calculated this risk score for each patient in the primary dataset and divided patients into high$(n=92)$ and low-risk groups $(n=92)$ based on median risk scores in the primary dataset. Risk scores, OS, 
and expression profiles of the four IncRNAs were are visualised in Figure 3A-C. Kaplan-Meier analysis demonstrated a significantly worse prognosis in the high-risk group than in the low-risk group $(p<0.001$, Figure 3D). Next, we utilized time-dependent receiver operating characteristic curves to assess the performance of the prognostic features for prediction of OS (Figure 3E-G). This revealed we were able to obtain AUC (area under the curve) values of $0.738,0.737$, and 0.637 at 1,2 , and 3 years, respectively, indicating a high accuracy of the prediction model. From this, we concluded that the prognostic features we had selected performed well for risk and overall survival prediction in the primary dataset.

We further validated the predictive performance of the prognostic features using the entire dataset $(n=364)$. The median risk score of the primary dataset was used as the threshold to divide the entire dataset into a high- $(n=191)$ and a low-risk group $(n=173)$. The risk score, OS status, and four OS-related IncRNAs in the entire dataset exhibited a similar trend as results of the primary dataset (Figure 4A-C). We also found significant differences in survival between the high- and low-risk groups (Figure 4D). To evaluate the ability to predict survival at 1,2 , and 3 years, we again calculated calculated AUCs from timedependent receiver operating characteristic curves (Figure 4E-G). AUCs were 0.702, 0.714, and 0.632, respectively. While AUC values were decreased slightly compared with the primary dataset, they still indicated an excellent predictive performance of prognostic risk score.

\section{Table 3. Multivariable Cox analysis of IncRNAs in the primary dataset.}

\begin{tabular}{llll} 
id & coef & HR $(95 \% \mathrm{Cl})$ & pvalue \\
\hline AC138904.1 & -0.326 & $0.722(0.515-1.011)$ & 0.058 \\
\hline DNM30S & 0.100 & $1.105(1.005-1.214)$ & 0.039 \\
\hline USP30-AS1 & -0.172 & $0.842(0.718-0.987)$ & 0.034 \\
\hline FOXP4-AS1 & -0.248 & $0.780(0.614-0.991)$ & 0.042
\end{tabular}

\section{Independent prognostic performance of prognostic features}

Using univariate Cox regression analysis, we found that the prognostic risk score acted as an independent prognostic factor in both datasets we evaluated $(H R=1.6013$ and $p=1.79 * e-5$ in the primary dataset, and $\mathrm{HR}=1.5758 \mathrm{p}=5.69 * \mathrm{e}-7$ in the entire dataset) (Table 4, Figure 5A). Multivariable COX regression analysis revealed that the risk score was still an independent prognostic feature even after correction for other confounders $\left(H R=1.5680, p=3.69 * e-5\right.$ in the primary dataset; $H R=1.5672, p=5.05^{*} e-7$ in the entire dataset) (Table 4, Figure 5B). To evaluate predictive accuracy of the risk score, the receiver operating characteristic curves were plotted and further AUC values were calculated for the entire dataset (Figure 5C). This revealed that assessing prognosis at three years, the ferroptosis-related IncRNA risk score performed better than age or grade (AUCs of prognostic risk score, age, and grade were 0.714 , $0.631,0.555$, respectively). 
Table 4. Univariate and multivariable Cox proportional hazards regression analysis of the prognostic risk score and clinical risk factors in the entire dataset.

\begin{tabular}{lllll} 
Characteristic & \multicolumn{2}{l}{ Univariate analysis } & & Multivariate analysis \\
\cline { 2 - 5 } & HR $(95 \% \mathrm{Cl})$ & pvalue & HR $(95 \% \mathrm{Cl})$ & pvalue \\
\hline Age $(\geq 65$ vs. $<65)$ & $1.019(1.006-1.033)$ & 0.005 & $1.020(1.007-1.034)$ & 0.003 \\
\hline grade(GI-GIV) & $1.387(0.922-2.084)$ & 0.116 & $1.267(0.840-1.911)$ & 0.259 \\
\hline riskScore & $1.576(1.319-1.883)$ & $<0.001$ & $1.567(1.315-1.867)$ & $<0.001$
\end{tabular}

\section{Production of nomograms based on prognostic features}

Traditional clinical risk factors remain important predictors of OS in OC patients. To better predict the OS of OC patients, prognostic features and a number of traditional clinical factors have previously been combined to develop models for OS prediction. Examining independent prognostic performance in the entire dataset, we discovered that in addition to ferroptosis-related IncRNAs, age was also a prognostic marker, which may have been overlooked due to the smaller sample size in the primary dataset. We therefore created a nomogram based on these two risk factors (ferroptosis-related IncRNA prognostic risk score and age) and utilized it to predict 1, 2 , and 3 year survival rates (Figure 6A). In the clinic, this simple graphical tool could be utilized to easily calculate the survival probabilities of each OC patient. We used the $\mathrm{C}$-index and calibration curves to evaluate the predictive effectiveness of the nomograms (Figure 6BD) which revealed that these nomograms were good predictors of survival time for OC patients.

\section{Enrichment analysis}

In order to infer the potential functions of ferroptosis-related IncRNAs in the development of OC, we identified 417 IncRNA-mRNA pairs (|R2|>0.6, <0.001) (Supplementary Table 2) and subjected the coexpressed mRNAs to GO and KEGG pathway analysis. GO results showed that the co-expressed mRNAs were enriched for genes involved in immune response and immune regulation, such as the activation of $T$ cells (Figure 7A). KEGG results revealed that the 417 co-expressed mRNAs were predominantly involved in Human T-lymphotropic virus 1 infection, Epstein-Barr virus infection, antigen handling, and presentation (Figure 7B).

\section{Discussion}

Survival times for OC patients vary widely, spanning from less than 5 months to more than 10 years [17]. Nonetheless, due to a lack of choice in treatment approaches, all patients are treated relatively similarly. Prognostic features may help to accurately identify patients with different survival times and to individualize treatment. Over the past decades, clinical characteristics such as age and a range of serum markers have been used to determine tumour progression and predict the prognosis of OC patients. However, these clinical characteristics factors are often not sufficiently accurate prognostic predictors to help improve treatment options. In this study, we developed and validated a four IncRNA-based 
prognostic risk score using data from the TCGA cohort for which both clinical and gene expression data are available.

With the intensive study of various common cancers, there is growing evidence that ferroptosis contributes to cancer development $[18,19,20]$. Ferroptosis acts as a double-edged sword [21]: it can cause immunosuppression by triggering a cellular inflammatory response, which in turn accelerates tumour growth [22]; on the other hand, pharmacological induction of ferroptosis can inhibit tumour growth [23]. Ferroptosis has therefore shown great promise in cancer treatment, particularly in cancers that are resistant to conventional therapies [24]. Ferroptosis-associated drugs such as artesunate, FIN56, FINO2, erastin, and sorafenib have been successively discovered to exert antitumor effects. For instance, artesunate, a herbal medicine originally used for malaria control, has been found to inhibit the growth of OC cells via induction of reactive oxygen species-related (ROS) ferroptosis $[25,26]$. With increasing research, more ferroptosis-associated genes are being identified. Due to a lack of systematic reports, previous studies have tended to identify ferroptosis-related genes only based on existing literature, which may have resulted in some ferroptosis-related genes being overlooked [27]. The FerrDb database includes 259 regulators derived from ferroptosis articles in the PubMed database [28]. In this study, we used the FerrDb database to identify a comprehensive list of ferroptosis-related genes.

Our study identified four ferroptosis-related IncRNAs (FOXP4-AS1, USP30-AS1, DNM30S, AC138904.1) with a prognostic role in OC. Among these four IncRNAs, three IncRNAs (FOXP4-AS1, USP30-AS1, DNM30S) have been previously studied either in OC or other cancers. Among these, FOXP4-AS1 and USP30-AS1 were associated with a good prognosis for OC, while DNM3OS was associated with a poor prognosis for OC. For instance, FOXP4-AS1 has been proposed an emerging cancer-related biomarker. While a study by Huang et al. identified inconsistent effects of FOXP4-AS1 in different types of cancers [29], Yang et al. found that FOXP4-AS1 promoted osteosarcoma development by binding to LSD1 and EZH2 to downregulate LATS1 [30], and similar effects have been reported in prostate, cervical, and nasopharyngeal cancers [31,32,33]. Interestingly, the role of FOXP4-AS1 in OC may be different from other cancers. Liao et al. suggested that FOXP4-AS1 improves OC prognosis by participation in the CTLA4 pathway [34]. The authors found that FOXP4-AS1 was highly expressed in the low-risk group of OC patients. Based on these results and our own study, we infer that FOXP4-AS1 may be associated with a favourable OC prognosis. USP30-AS1 is transcribed from the antisense strand of the autophagy-related USP30 gene located on chromosome 12 [35]. In our study, elevated levels of USP30-AS1 was associated with an improved prognosis. This is again consistent with reports from previous studies which found abnormal expression of USP30-AS1 in ovarian, bladder, and cervical cancers as well as melanoma, where it acted as a good prognostic feature $[36,37,38,39]$. Wang et al. showed that the IncRNA DNM30S may promote cell proliferation, invasion, and metastasis of hepatocellular carcinoma [40]. Similarly, DNM3OS has been shown to positively regulate SMAD6 in retinoblastoma via competitive interaction with miR-134$5 p$, where high SMAD6 expression promotes tumour cell proliferation, migration, and epithelialmesenchymal transition [41]. Another previous study reported that DNM30S knockdown resulted in altered EMT-related genes/pathways, mesenchymal to epithelial transformation, and reduced cell migration and invasion, which suggested that high DNM30S expression may lead to a reduced survival 
rate in OC patients [42]. He et al. found that DNM3OS promoted OC progression via regulation of the miR193a-3p/MAP3K3 axis [43], which again suggested that DNM30S may represent a poor prognostic factor in OC, and DNM3OS has also been reported as a molecular marker for cancer progression in a variety of different cancer types $[44,45,46]$. In conclusion, the abovementioned three IncRNAs are thought to be involved in the development of $\mathrm{OC}$ or other cancers, and may represent therapeutic targets in $\mathrm{OC}$. The other ferroptosis-related IncRNA in our prognostic risk score, AC138904.1, has been rarely reported, and the present study may provide a new perspective on its functional pathways and involvement in ovarian carcinogenesis and progression.

To further explore how the IncRNAs may be involved in OC development, we performed a functional enrichment analysis and found that the risk score-associated genes were highly associated with the immune response. $\mathrm{GO}$ analysis identified a significant enrichment in pathways linked to the activation and regulation of $\mathrm{T}$ cells, which suggested that T-cell activation may be closely linked to OC development. Yeung et al. previously showed that ISG15 can inhibit OC progression via activation of CD8+ T cells [47]. CD8+ T cells have been reported to inhibit cysteine uptake by tumor cells and may promote ferroptosis in cancer cells by releasing IFNy, which may represent a novel anti-tumour mechanism $[48,49]$. Akyol et al. found that HSP10 produced by ovarian tumour cells suppressed the expression of CD3-zeta, , a key component of T cell activation, in T cells [50], and OC patients with lower T cell CD3-zeta expression have been found to exhibit shorter survival times [51]. In addition, IL4I1 has been found to impair T-cell activation, block $\mathrm{T}$ cell proliferation and differentiation, and thus promote $\mathrm{OC}$ proliferation, migration, and invasion [52]. From this, we hypothesized that $T$ cell activation may prolong OC patient survival, while $T$ cell suppression may be closely associated with low survival in $\mathrm{OC}$ patients. In addition, the negative regulation of immune system processes was significantly enriched in ferroptosis-associated IncRNAs. The immune system is known to play a significant role in cancer progression, and a previous study reported progressive impairment of the immune response in patients with advanced OC [53,54]. The most significant cellular component enrichment in $\mathrm{GO}$ analysis was the external side of the plasma membrane, including proteins which are attached, immobilised or embedded in the plasma membrane. LAG-3 is a cell surface molecule with diverse biological effects on T cell function. A study by Matsuzaki et al. found that LAG-3 indirectly inhibited T cell proliferation, which the authors proposed to be associated with a reduction in T cell receptor-induced calcium flux [55]. In conclusion, we may speculate that proteins attached to the external side of the plasma membrane are intimately involved in the development of OC.

KEGG results revealed that Human T-lymphotropic virus 1 infection, Epstein-Barr virus infection, and antigen handling and presentation pathways were significantly enriched. Human T-lymphotropic virus 1 (HTLV-1) is a retrovirus that can induce adult T cell leukaemia [56]. So far, there have been no studies reporting an association between HTLV-1 and OC. However, HTLV-1 infection can promote T cell proliferation by tampering with several core signalling pathways of T cell function [57], and the relationship between $T$ cell function and $O C$ has been demonstrated in several studies $[49,50,52]$. From this, we speculate that HTLV-1 may regulate OC via T cell function and offers a new direction for the treatment of OC. Epstein-Barr virus (EBV) is a double-stranded DNA virus [58]. In two different studies, the EBV positivity rate has been reported to be lower in the normal group than in OC patient groups $[59,60]$. It 
has moreover been reported that the miR-BART7 of EBV was more highly expressed in the OC patients than in cancer-free controls, and miR-BART7 may be related to poor OC prognosis [61]. Littman et al. showed that elevated EBV antibody titers may lead to increased risk of OC [62]. Although the potential role of EBV in OC has not been extensively researched, its role in other cancers has been clearly demonstrated $[63,64]$. In addition to HTLV- 1 and EBV, pathways involved in processing and presentation of antigens were significantly enriched in KEGG analysis. A previous study showed that CCL22, expressed by macrophages in the tumour microenvironment of $\mathrm{OC}$ patients, helped to attract regulatory $\mathrm{T}$ cells to the tumour environment [65]. Interestingly, regulatory $T$ cells have been shown to be related to a higher risk of death in OC patients [66]. Macrophage-expressed B7-H4 has also been found to suppress tumorassociated antigen-specific T cell immunity, and B7-H4 expression levels were negatively associated with patient survival $[67,68]$. Plasmacytoid dendritic cells (pDCs) are innate immune cells that appear in peripheral lymphoid organs and the circulation. A review reported that OC-related pDCs induce the activation of CD8+ Treg cells and promote tumour angiogenesis $[68,69]$. Therefore, we speculated that macrophages, plasmacytoid dendritic cells, and other antigen-presenting cells, may indirectly influence OC prognosis. In short, the four prognostic ferroptosis-related IncRNAs identified in this study are thought to be involved in $\mathrm{OC}$ development and prognosis.

We developed a prognostic profile of four IncRNAs associated with iron toxicity, and found it could effectively identify patients with high-risk OC. As OC has been studied closely, many prognostic markers have been identified. However, some studies screened prognostic markers with criteria that ignored the clinical significance by limiting their focus to the statistical performance [70]. Age has been reported as a survival and prognostic factor for $\mathrm{OC}$ patients in a recent study [71]. In this study, we analysed the prognostic value of clinical risk factors and prognostic features. Finally, we constructed a nomogram based on the prognostic risk score and age for easy clinical implementation [72].

The current study has several limitations. Firstly, some clinical data (e.g., stage) were not collected by TCGA, so we were unable to conduct a full survival analysis for these factors. Second, the prognostic features we established need to be validated in other independent cohorts for further confirmation and to ensure their robustness. Third, further experiments are needed to explore how ferroptosis-related IncRNAs are involved in $\mathrm{OC}$ development.

\section{Conclusion}

We successfully constructed a prognostic risk score based on four ferroptosis-related IncRNAs that can be used as a new biomarker for the prediction OC patient survival. Additionally, this novel signature may enable further insights into the association between ferroptosis and tumorigenesis for clinical ferroptosisrelated targeted therapies. For easy clinical implementation, we developed a prognostic feature-based nomogram which can aid in the individualized management of OC patients.

\section{Abbreviations}




\begin{tabular}{|ll|}
\hline Long non-coding RNAs & IncRNAs \\
\hline area under the curve & AUC \\
\hline Gene Ontology & GO \\
\hline Kyoto Encyclopedia of Genes and Genomes & KEGG \\
\hline overall survival & OS \\
\hline regulated cell death & RCD \\
\hline glutathione peroxidase 4 & GPX4 \\
\hline Ferroportin & FPN \\
\hline Transferrin receptor protein 1 & TfR1 \\
\hline Cancer Genome Atlas & TCGA \\
\hline Genotype-Tissue Expression & GTEx \\
\hline differentially expressed genes & DEGs \\
\hline Ovarian cancer & OC \\
\hline hazard ratio & HR \\
\hline Akaike information criterion & AIC \\
\hline reactive oxygen species & ROS \\
\hline Human T-lymphotropic virus 1 & HTLV-1 \\
\hline Epstein-Barr virus & EBV \\
\hline Plasmacytoid dendritic cells & pDCs \\
\hline
\end{tabular}

\section{Declarations}

Ethics approval and consent to participate: Not applicable.

Consent for publication: Not applicable.

Availability of data and materials: The datasets generated and analysed during the current study are available in the TCGA and GTEx datasets that provide free online tools and resources.

Competing interests: The authors declare that they have no competing interests.

Funding:This study was supported by Science and Technology Project of Department of Education of Zhejiang Province (No.Y202044608); Basic Public Welfare Research Project of Zhejiang Province (Grant no. LGN19C190004). 
Authors' contributions: Chen, first author: conception of the research content idea, design of the research proposal, finding data and writing the paper. Li: data processing, data analysis, visual presentation of research results. Qi, corresponding author: theoretical guidance of the research proposal, review and revision of the first draft, responsible for communication with the journal for submission of the manuscript.

Acknowledgements: The authors thank the free online tools and resources from TCGA, FerrDb and GTEx datasets.

\section{References}

1. Stewart C, Ralyea C, Lockwood S. Ovarian Cancer: An Integrated Review. Semin Oncol Nurs. 2019 Apr;35(2):151-156. doi: 10.1016/j.soncn.2019.02.001.

2. Siegel RL, Miller KD, Fuchs HE, Jemal A. Cancer Statistics, 2021. CA Cancer J Clin. 2021 Jan;71(1):733. doi: $10.3322 /$ caac. 21654 .

3. Bast RC Jr, Hennessy B, Mills GB. The biology of ovarian cancer: new opportunities for translation. Nat Rev Cancer. 2009 Jun;9(6):415-28. doi: 10.1038/nrc2644.

4. Reid BM, Permuth JB, Sellers TA. Epidemiology of ovarian cancer: a review. Cancer Biol Med. 2017 Feb;14(1):9-32. doi: 10.20892/j.issn.2095-3941.2016.0084.

5. Lee JY, Kim S, Kim YT, Lim MC, Lee B, Jung KW, Kim JW, Park SY, Won YJ. Changes in ovarian cancer survival during the 20 years before the era of targeted therapy. BMC Cancer. 2018 May 29;18(1):601. doi: 10.1186/s12885-018-4498-z.

6. Qiu JJ, Lin YY, Ye LC, Ding JX, Feng WW, Jin HY, Zhang Y, Li Q, Hua KQ. Overexpression of long noncoding RNA HOTAIR predicts poor patient prognosis and promotes tumor metastasis in epithelial ovarian cancer. Gynecol Oncol. 2014 Jul;134(1):121-8. doi: 10.1016/j.ygyno.2014.03.556.

7. Zhao J, Du P, Cui P, Qin Y, Hu C, Wu J, Zhou Z, Zhang W, Qin L, Huang G. LncRNA PVT1 promotes angiogenesis via activating the STAT3/VEGFA axis in gastric cancer. Oncogene. 2018 Jul;37(30):4094-4109. doi: 10.1038/s41388-018-0250-z.

8. Zhang LQ, Yang SQ, Wang Y, Fang Q, Chen XJ, Lu HS, Zhao LP. Long Noncoding RNA MIR4697HG Promotes Cell Growth and Metastasis in Human Ovarian Cancer. Anal Cell Pathol (Amst). 2017;2017:8267863. doi: 10.1155/2017/8267863.

9. Shen $Y$, Peng $X$, Shen $C$. Identification and validation of immune-related IncRNA prognostic signature for breast cancer. Genomics. 2020 May;112(3):2640-2646. doi: 10.1016/j.ygeno.2020.02.015.

10. Chen X, Comish PB, Tang D, Kang R. Characteristics and Biomarkers of Ferroptosis. Front Cell Dev Biol. 2021 Jan 21;9:637162. doi: 10.3389/fcell.2021.637162.

11. Dixon SJ, Lemberg KM, Lamprecht MR, Skouta R, Zaitsev EM, Gleason CE, Patel DN, Bauer AJ, Cantley AM, Yang WS, Morrison B 3rd, Stockwell BR. Ferroptosis: an iron-dependent form of nonapoptotic cell death. Cell. 2012 May 25;149(5):1060-72. doi: 10.1016/j.cell.2012.03.042. 
12. Yagoda N, von Rechenberg M, Zaganjor E, Bauer AJ, Yang WS, Fridman DJ, Wolpaw AJ, Smukste I, Peltier JM, Boniface JJ, Smith R, Lessnick SL, Sahasrabudhe S, Stockwell BR. RAS-RAF-MEKdependent oxidative cell death involving voltage-dependent anion channels. Nature. 2007 Jun 14;447(7146):864-8. doi: 10.1038/nature05859.

13. Yang WS, Stockwell BR. Ferroptosis: Death by Lipid Peroxidation. Trends Cell Biol. 2016 Mar;26(3):165-176. doi: 10.1016/j.tcb.2015.10.014.

14. Chen X, Kang R, Kroemer G, Tang D. Broadening horizons: the role of ferroptosis in cancer. Nat Rev Clin Oncol. 2021 May;18(5):280-296. doi: 10.1038/s41571-020-00462-0.

15. Basuli D, Tesfay L, Deng Z, Paul B, Yamamoto Y, Ning G, Xian W, McKeon F, Lynch M, Crum CP, Hegde P, Brewer M, Wang X, Miller LD, Dyment N, Torti FM, Torti SV. Iron addiction: a novel therapeutic target in ovarian cancer. Oncogene. 2017 Jul 20;36(29):4089-4099. doi: 10.1038/onc.2017.11.

16. Roett MA, Evans P. Ovarian cancer: an overview. Am Fam Physician. 2009 Sep 15;80(6):609-16.

17. Mok SC, Bonome T, Vathipadiekal V, Bell A, Johnson ME, Wong KK, Park DC, Hao K, Yip DK, Donninger H, Ozbun L, Samimi G, Brady J, Randonovich M, Pise-Masison CA, Barrett JC, Wong WH, Welch WR, Berkowitz RS, Birrer MJ. A gene signature predictive for outcome in advanced ovarian cancer identifies a survival factor: microfibril-associated glycoprotein 2. Cancer Cell. 2009 Dec 8;16(6):521-32. doi: 10.1016/j.ccr.2009.10.018.

18. Yang WS, SriRamaratnam R, Welsch ME, Shimada K, Skouta R, Viswanathan VS, Cheah JH, Clemons PA, Shamji AF, Clish CB, Brown LM, Girotti AW, Cornish VW, Schreiber SL, Stockwell BR. Regulation of ferroptotic cancer cell death by GPX4. Cell. 2014 Jan 16;156(1-2):317-331. doi: 10.1016/j.cell.2013.12.010.

19. Sun X, Ou Z, Xie M, Kang R, Fan Y, Niu X, Wang H, Cao L, Tang D. HSPB1 as a novel regulator of ferroptotic cancer cell death. Oncogene. 2015 Nov 5;34(45):5617-25. doi: 10.1038/onc.2015.32.

20. Yu H, Guo P, Xie X, Wang Y, Chen G. Ferroptosis, a new form of cell death, and its relationships with tumourous diseases. J Cell Mol Med. 2017 Apr;21(4):648-657. doi: 10.1111/jcmm.13008.

21. Chen X, Kang R, Kroemer G, Tang D. Broadening horizons: the role of ferroptosis in cancer. Nat Rev Clin Oncol. 2021 May;18(5):280-296. doi: 10.1038/s41571-020-00462-0.

22. Guo J, Xu B, Han Q, Zhou H, Xia Y, Gong C, Dai X, Li Z, Wu G. Ferroptosis: A Novel Anti-tumor Action for Cisplatin. Cancer Res Treat. 2018 Apr;50(2):445-460. doi: 10.4143/crt.2016.572.

23. Murao A, Aziz M, Wang H, Brenner M, Wang P. Release mechanisms of major DAMPs. Apoptosis. 2021 Apr;26(3-4):152-162. doi: 10.1007/s10495-021-01663-3.

24. Hassannia B, Vandenabeele P, Vanden Berghe T. Targeting Ferroptosis to Iron Out Cancer. Cancer Cell. 2019 Jun 10;35(6):830-849. doi: 10.1016/j.ccell.2019.04.002.

25. Greenshields AL, Shepherd TG, Hoskin DW. Contribution of reactive oxygen species to ovarian cancer cell growth arrest and killing by the anti-malarial drug artesunate. Mol Carcinog. 2017 Jan;56(1):7593. doi: $10.1002 / \mathrm{mc} .22474$.

26. Roh JL, Kim EH, Jang H, Shin D. Nrf2 inhibition reverses the resistance of cisplatin-resistant head and neck cancer cells to artesunate-induced ferroptosis. Redox Biol. 2017 Apr;11:254-262. doi: 
10.1016/j.redox.2016.12.010.

27. Ye Y, Dai Q, Li S, He J, Qi H. A Novel Defined Risk Signature of the Ferroptosis-Related Genes for Predicting the Prognosis of Ovarian Cancer. Front Mol Biosci. 2021 Apr 1;8:645845. doi: 10.3389/fmolb.2021.645845.

28. Zhou N, Bao J. FerrDb: a manually curated resource for regulators and markers of ferroptosis and ferroptosis-disease associations. Database (Oxford). 2020 Jan 1;2020:baaa021. doi: 10.1093/database/baaa021.

29. Huang Y, Ling A, Pareek S, Huang RS. Oncogene or tumor suppressor? Long noncoding RNAs role in patient's prognosis varies depending on disease type. Transl Res. 2021 Apr;230:98-110. doi: 10.1016/j.trsl.2020.10.011.

30. Yang L, Ge D, Chen X, Qiu J, Yin Z, Zheng S, Jiang C. FOXP4-AS1 participates in the development and progression of osteosarcoma by downregulating LATS1 via binding to LSD1 and EZH2. Biochem Biophys Res Commun. 2018 Aug 25;502(4):493-500. doi: 10.1016/j.bbrc.2018.05.198.

31. Wu X, Xiao Y, Zhou Y, Zhou Z, Yan W. LncRNA FOXP4-AS1 is activated by PAX5 and promotes the growth of prostate cancer by sequestering miR-3184-5p to upregulate FOXP4. Cell Death Dis. 2019 Jun 17;10(7):472. doi: 10.1038/s41419-019-1699-6.

32. Zhao J, Yang T, Li L. LncRNA FOXP4-AS1 Is Involved in Cervical Cancer Progression via Regulating miR-136-5p/CBX4 Axis. Onco Targets Ther. 2020 Mar 19;13:2347-2355. doi: 10.2147/OTT.S241818.

33. Zhong LK, Zhou J, He X, He BF, Zhou XW, Zhu JL, Liu J, Qiu YH. Long non-coding RNA FOXP4-AS1 acts as an adverse prognostic factor and regulates proliferation and apoptosis in nasopharyngeal carcinoma. Eur Rev Med Pharmacol Sci. 2020 Aug;24(15):8008-8016. doi: 10.26355/eurrev_202008_22484.

34. Liao $\mathrm{C}$, Wang A, Ma Y, Liu H. Long non-coding RNA FOXP4-AS1 is a prognostic biomarker and associated with immune infiltrates in ovarian serous cystadenocarcinoma. Medicine (Baltimore). 2021 Oct 8;100(40):e27473. doi: 10.1097/MD.0000000000027473.

35. Wang N, Li J, Xin Q, Xu N. USP30-AS1 contributes to mitochondrial quality control in glioblastoma cells. Biochem Biophys Res Commun. 2021 Dec 3;581:31-37. doi: 10.1016/j.bbrc.2021.10.006.

36. Meng C, Zhou JQ, Liao YS. Autophagy-related long non-coding RNA signature for ovarian cancer. J Int Med Res. 2020 Nov;48(11):300060520970761. doi: 10.1177/0300060520970761.

37. Ding Y, Li T, Li M, Tayier T, Zhang M, Chen L, Feng S. A Novel Autophagy-Related IncRNA Gene Signature to Improve the Prognosis of Patients with Melanoma. Biomed Res Int. 2021 Jun 18;2021:8848227. doi: 10.1155/2021/8848227.

38. Sun Z, Jing C, Xiao C, Li T. An autophagy-related long non-coding RNA prognostic signature accurately predicts survival outcomes in bladder urothelial carcinoma patients. Aging (Albany NY). 2020 Aug 29;12(15):15624-15637. doi: 10.18632/aging.103718.

39. Liu J, Liu Y, Gao F, Zhang J, Pan J, Liu Y, Zhu H. Comprehensive study of a novel immune-related IncRNA for prognosis and drug treatment of cervical squamous cell carcinoma. Am J Transl Res. 2021 Oct 15;13(10):11771-11785. 
40. Wang W, Wang Q, Huang DB, Sun QK, Wu SS, Zhao YJ, Jia W, Hu DS, He YF. Tumor-associated mesenchymal stem cells promote hepatocellular carcinoma metastasis via a DNM30S/KDM6B/TIAM1 axis. Cancer Lett. 2021 Apr 10;503:19-31. doi: 10.1016/j.canlet.2021.01.011.

41. Wang H, Ji X. SMAD6, positively regulated by the DNM30S-miR-134-5p axis, confers promoting effects to cell proliferation, migration and EMT process in retinoblastoma. Cancer Cell Int. 2020 Jan 22;20:23. doi: 10.1186/s12935-020-1103-8.

42. Mitra R, Chen X, Greenawalt EJ, Maulik U, Jiang W, Zhao Z, Eischen CM. Decoding critical long noncoding RNA in ovarian cancer epithelial-to-mesenchymal transition. Nat Commun. 2017 Nov 17;8(1):1604. doi: 10.1038/s41467-017-01781-0.

43. He L, He G. DNM3OS Facilitates Ovarian Cancer Progression by Regulating miR-193a-3p/MAP3K3 Axis. Yonsei Med J. 2021 Jun;62(6):535-544. doi: 10.3349/ymj.2021.62.6.535.

44. Fang $X$, Tang Z, Zhang H, Quan H. Long non-coding RNA DNM30S/miR-204-5p/HIP1 axis modulates oral cancer cell viability and migration. J Oral Pathol Med. 2020 Oct;49(9):865-875. doi:

10.1111/jop.13047. Epub 2020 Jun 20.

45. Wang R, Zhang M, Ou Z, He W, Chen L, Zhang J, He Y, Xu R, Jiang S, Qi L, Wang L. Long noncoding RNA DNM30S promotes prostate stromal cells transformation via the miR-29a/29b/COL3A1 and miR-361/TGFß1 axes. Aging (Albany NY). 2019 Nov 6;11(21):9442-9460. doi:

10.18632/aging.102395.

46. Wang S, Ni B, Zhang Z, Wang C, Wo L, Zhou C, Zhao Q, Zhao E. Long non-coding RNA DNM30S promotes tumor progression and EMT in gastric cancer by associating with Snail. Biochem Biophys Res Commun. 2019 Mar 26;511(1):57-62. doi: 10.1016/j.bbrc.2019.02.030.

47. Yeung TL, Tsai CC, Leung CS, Au Yeung CL, Thompson MS, Lu KH, Freedman RS, Birrer MJ, Wong KK, Mok SC. ISG15 Promotes ERK1 ISGylation, CD8+ T Cell Activation and Suppresses Ovarian Cancer Progression. Cancers (Basel). 2018 Nov 22;10(12):464. doi: 10.3390/cancers10120464.

48. Immunotherapy Activates Unexpected Cell Death Mechanism. Cancer Discov. 2019 Jul;9(7):OF2. doi: 10.1158/2159-8290.CD-NB2019-058.

49. Wang W, Green M, Choi JE, Gijón M, Kennedy PD, Johnson JK, Liao P, Lang X, Kryczek I, Sell A, Xia H, Zhou J, Li G, Li J, Li W, Wei S, Vatan L, Zhang H, Szeliga W, Gu W, Liu R, Lawrence TS, Lamb C, Tanno Y, Cieslik M, Stone E, Georgiou G, Chan TA, Chinnaiyan A, Zou W. CD8+ T cells regulate tumour ferroptosis during cancer immunotherapy. Nature. 2019 May;569(7755):270-274. doi: 10.1038/s41586-019-1170-y.

50. Akyol S, Gercel-Taylor C, Reynolds LC, Taylor DD. HSP-10 in ovarian cancer: expression and suppression of T-cell signaling. Gynecol Oncol. 2006 Jun;101(3):481-6. doi: 10.1016/j.ygyno.2005.11.014.

51. Kuss I, Rabinowich H, Gooding W, Edwards R, Whiteside TL. Expression of zeta in T cells prior to interleukin-2 therapy as a predictor of response and survival in patients with ovarian carcinoma. Cancer Biother Radiopharm. 2002 Dec;17(6):631-40. doi: 10.1089/108497802320970235. 
52. Zhao H, Teng Y, Hao W, Li J, Li Z, Chen Q, Yin C, Yue W. Single-cell analysis revealed that IL4I1 promoted ovarian cancer progression. J Transl Med. 2021 Oct 30;19(1):454. doi: 10.1186/s12967021-03123-7.

53. Berek JS, Schultes BC, Nicodemus CF. Biologic and immunologic therapies for ovarian cancer. J Clin Oncol. 2003 May 15;21(10 Suppl):168s-174s. doi: 10.1200/JC0.2003.01.517.

54. Gordon AN, Schultes BC, Gallion H, Edwards R, Whiteside TL, Cermak JM, Nicodemus CF. CA125- and tumor-specific T-cell responses correlate with prolonged survival in oregovomab-treated recurrent ovarian cancer patients. Gynecol Oncol. 2004 Aug;94(2):340-51. doi: 10.1016/j.ygyno.2004.04.024.

55. Matsuzaki J, Gnjatic S, Mhawech-Fauceglia P, Beck A, Miller A, Tsuji T, Eppolito C, Qian F, Lele S, Shrikant $P$, Old LJ, Odunsi K. Tumor-infiltrating NY-ESO-1-specific CD8+ T cells are negatively regulated by LAG-3 and PD-1 in human ovarian cancer. Proc Natl Acad Sci U S A. 2010 Apr 27;107(17):7875-80. doi: 10.1073/pnas.1003345107.

56. Proietti FA, Carneiro-Proietti AB, Catalan-Soares BC, Murphy EL. Global epidemiology of HTLV-I infection and associated diseases. Oncogene. 2005 Sep 5;24(39):6058-68. doi:

10.1038/sj.onc.1208968.

57. Franchini G, Nicot C, Johnson JM. Seizing of T cells by human T-cell leukemia/lymphoma virus type 1. Adv Cancer Res. 2003;89:69-132. doi: 10.1016/s0065-230x(03)01003-0.

58. Zanella MC, Cordey S, Kaiser L. Beyond Cytomegalovirus and Epstein-Barr Virus: a Review of Viruses Composing the Blood Virome of Solid Organ Transplant and Hematopoietic Stem Cell Transplant Recipients. Clin Microbiol Rev. 2020 Aug 26;33(4):e00027-20. doi: 10.1128/CMR.00027-20.

59. Shokouh MR, Safaei A, Moattari A, Sarvari J. Association of Human Papilloma Virus and EpsteinBarr Virus with Ovarian Cancer in Shiraz, Southwestern Iran. Iran J Pathol. 2020 Fall;15(4):292-298. doi: 10.30699/ijp.2020.119681.2306.

60. Ingerslev K, Høgdall E, Skovrider-Ruminski W, Schnack TH, Lidang M, Høgdall C, Blaakaer J. The prevalence of EBV and CMV DNA in epithelial ovarian cancer. Infect Agent Cancer. 2019 Feb 26;14:7. doi: 10.1186/s13027-019-0223-z.

61. Pandya D, Mariani M, McHugh M, Andreoli M, Sieber S, He S, Dowell-Martino C, Fiedler P, Scambia G, Ferlini C. Herpes virus microRNA expression and significance in serous ovarian cancer. PLoS One. 2014 Dec 8;9(12):e114750. doi: 10.1371/journal.pone.0114750.

62. Littman AJ, Rossing MA, Madeleine MM, Tang MT, Yasui Y. Association between late age at infectious mononucleosis, Epstein-Barr virus antibodies, and ovarian cancer risk. Scand J Infect Dis. 2003;35(10):728-35. doi: 10.1080/00365540310016556.

63. Tokunaga M, Uemura Y, Tokudome T, Ishidate T, Masuda H, Okazaki E, Kaneko K, Naoe S, Ito M, Okamura $A$, et al. Epstein-Barr virus related gastric cancer in Japan: a molecular pathoepidemiological study. Acta Pathol Jpn. 1993 Oct;43(10):574-81. doi: 10.1111/j.14401827.1993.tb03233.x.

64. Tsao SW, Tsang CM, Lo KW. Epstein-Barr virus infection and nasopharyngeal carcinoma. Philos Trans R Soc Lond B Biol Sci. 2017 Oct 19;372(1732):20160270. doi: 10.1098/rstb.2016.0270. 
65. Curiel TJ, Coukos G, Zou L, Alvarez X, Cheng P, Mottram P, Evdemon-Hogan M, Conejo-Garcia JR, Zhang L, Burow M, Zhu Y, Wei S, Kryczek I, Daniel B, Gordon A, Myers L, Lackner A, Disis ML, Knutson $\mathrm{KL}$, Chen L, Zou W. Specific recruitment of regulatory T cells in ovarian carcinoma fosters immune privilege and predicts reduced survival. Nat Med. 2004 Sep;10(9):942-9. doi: 10.1038/nm1093.

66. You Y, Li Y, Li M, Lei M, Wu M, Qu Y, Yuan Y, Chen T, Jiang H. Ovarian cancer stem cells promote tumour immune privilege and invasion via CCL5 and regulatory T cells. Clin Exp Immunol. 2018 Jan;191(1):60-73. doi: 10.1111/cei.13044.

67. Kryczek I, Zou L, Rodriguez P, Zhu G, Wei S, Mottram P, Brumlik M, Cheng P, Curiel T, Myers L, Lackner A, Alvarez X, Ochoa A, Chen L, Zou W. B7-H4 expression identifies a novel suppressive macrophage population in human ovarian carcinoma. J Exp Med. 2006 Apr 17;203(4):871-81. doi: 10.1084/jem.20050930.

68. Wilke CM, Kryczek I, Zou W. Antigen-presenting cell (APC) subsets in ovarian cancer. Int Rev Immunol. 2011 Apr-Jun;30(2-3):120-6. doi: 10.3109/08830185.2011.567362.

69. Curiel TJ, Cheng P, Mottram P, Alvarez X, Moons L, Evdemon-Hogan M, Wei S, Zou L, Kryczek I, Hoyle G, Lackner A, Carmeliet P, Zou W. Dendritic cell subsets differentially regulate angiogenesis in human ovarian cancer. Cancer Res. 2004 Aug 15;64(16):5535-8. doi: 10.1158/0008-5472.CAN-04-1272.

70. Meng C, Zhou JQ, Liao YS. Autophagy-related long non-coding RNA signature for ovarian cancer. J Int Med Res. 2020 Nov;48(11):300060520970761. doi: 10.1177/0300060520970761.

71. Tingulstad S, Skjeldestad FE, Halvorsen TB, Hagen B. Survival and prognostic factors in patients with ovarian cancer. Obstet Gynecol. 2003 May;101(5 Pt 1):885-91. doi: 10.1016/s00297844(03)00123-6.

72. Balachandran VP, Gonen M, Smith JJ, DeMatteo RP. Nomograms in oncology: more than meets the eye. Lancet Oncol. 2015 Apr;16(4):e173-80. doi: 10.1016/S1470-2045(14)71116-7.

\section{Figures}


A

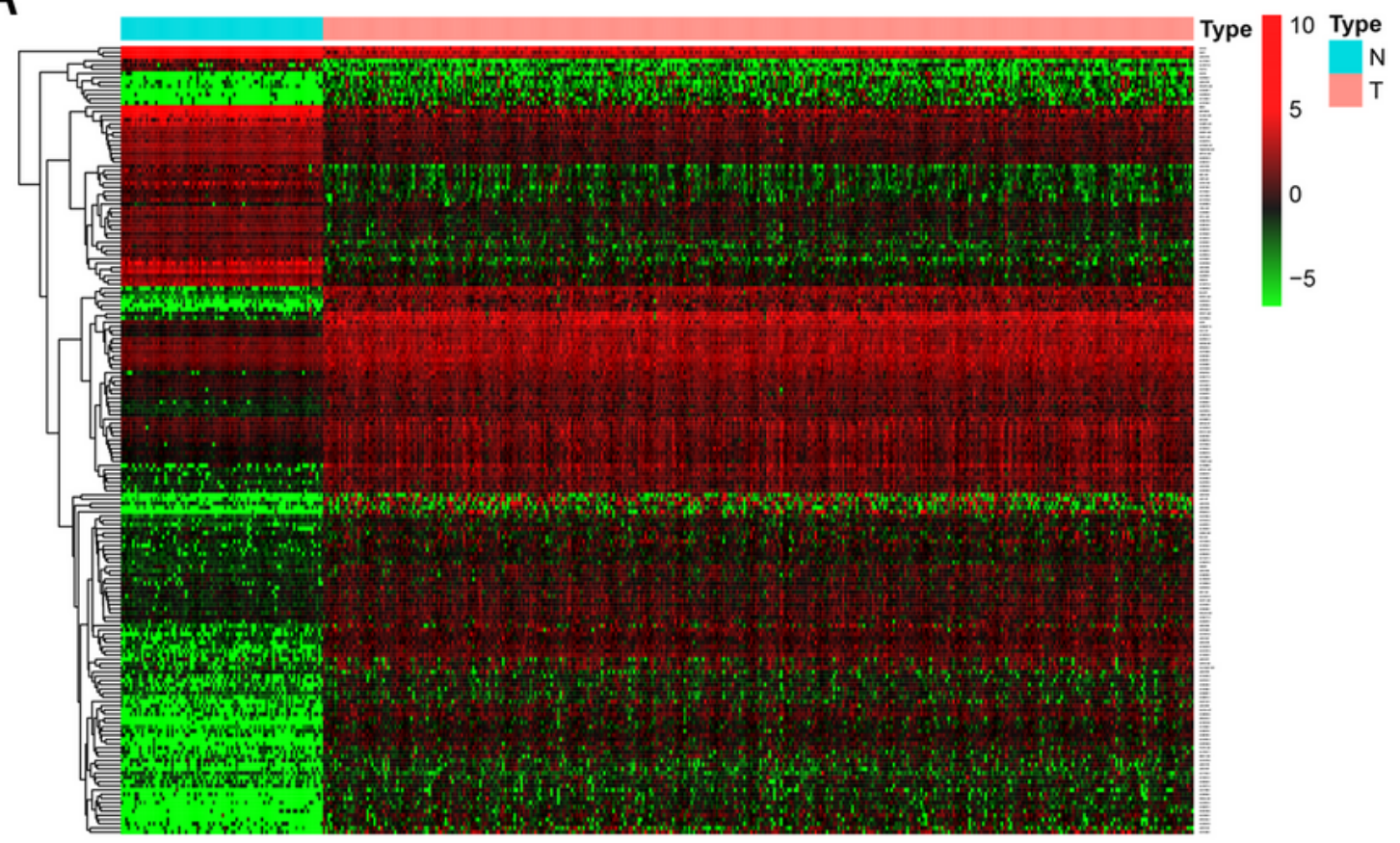

Volcano

B

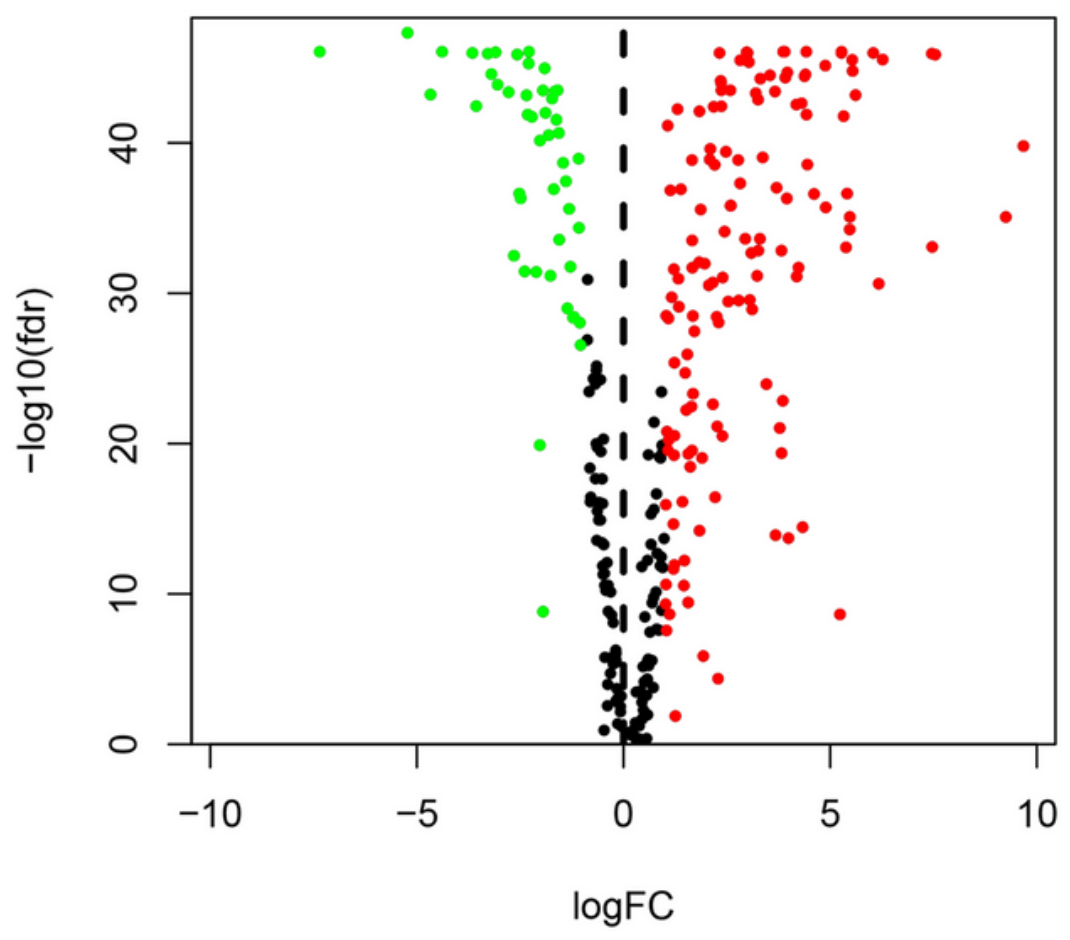

Figure 1

Identification of DEGs between ovarian cancer samples and normal ovarian tissue. (A) Heatmap of 315 ferrroptosis-related IncRNAs (green and red indicate lower and higher IncRNA expression, respectively) (B) Volcano plot of 315 ferrroptosis-related IncRNAs in ovarian cancer samples and normal ovarian tissue. 
A

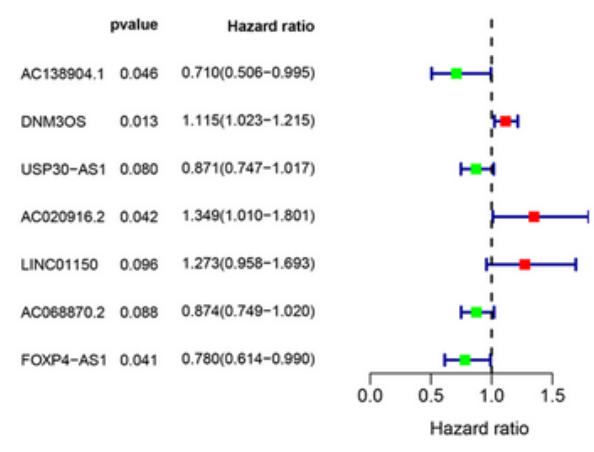

C
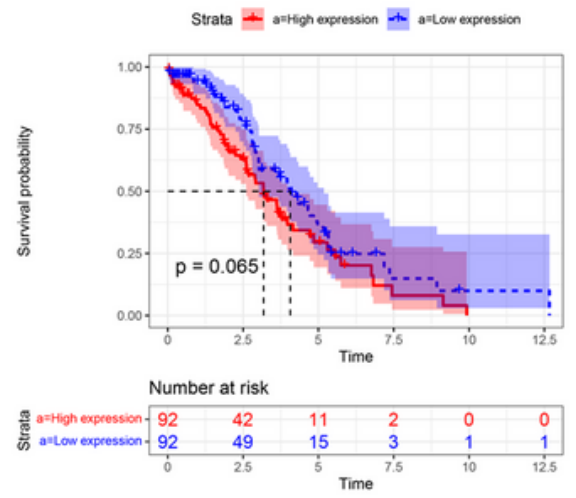

$E$
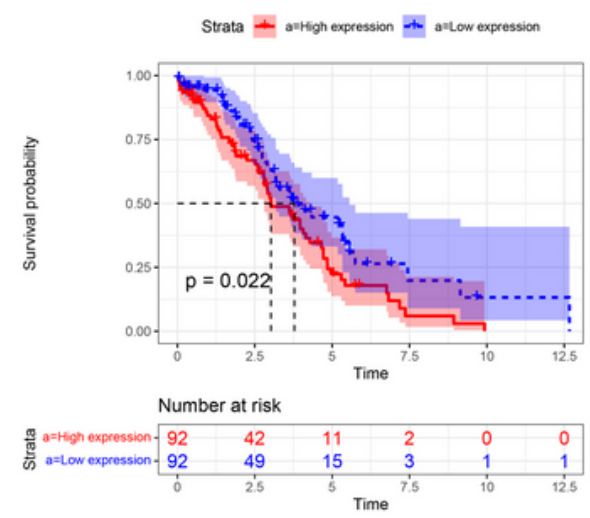

G

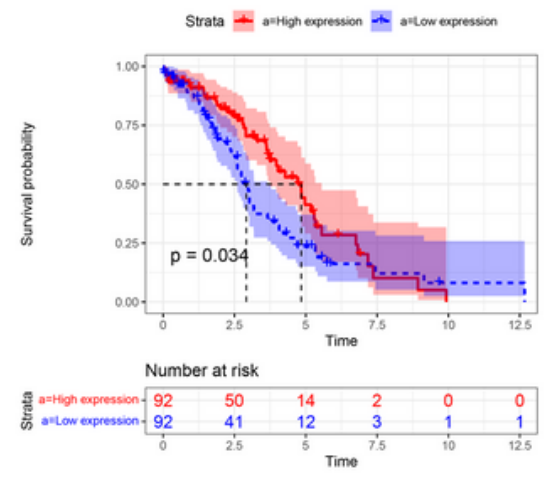

B

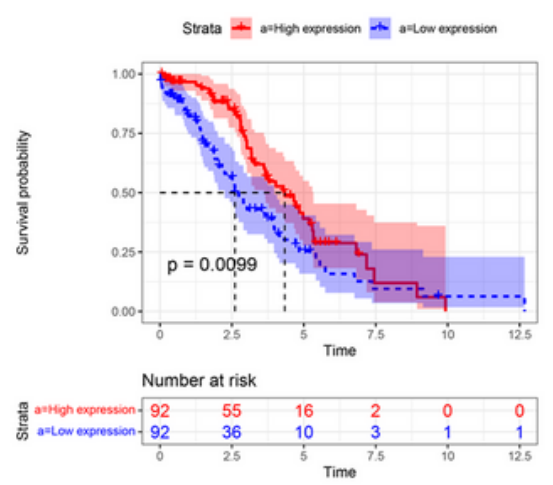

D
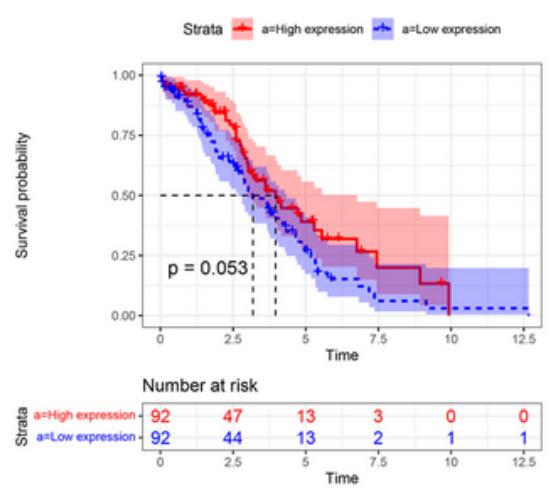

F
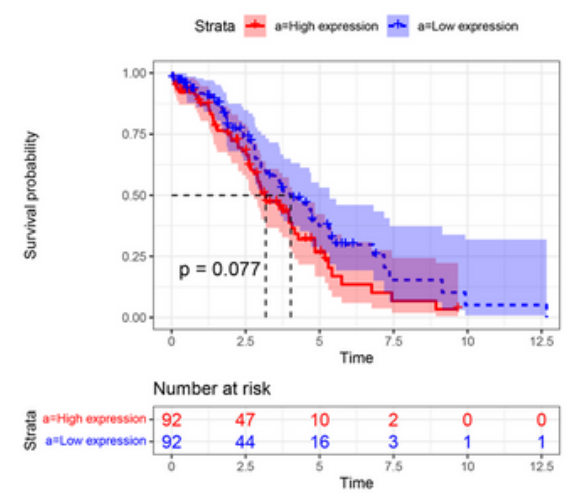

$\mathrm{H}$
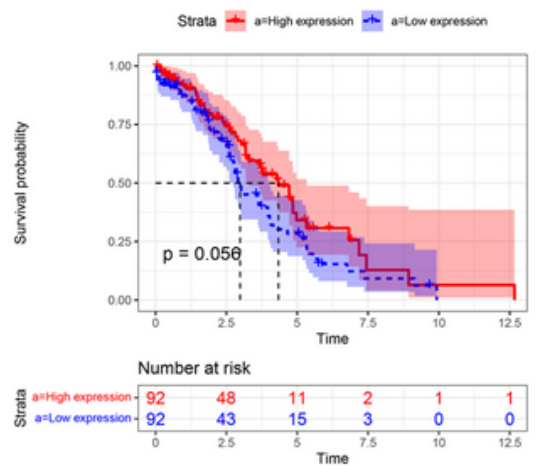

\section{Figure 2}

Seven candidate ferroptosis-related IncRNA associated with overall survival. (A) Forest plots of 7 OSrelated candidate genes identified by univariate Cox regression. (B-H) Single gene Kaplan-Meier curves assessing survival in association with expression of the seven IncRNAs AC138904.1, DNM30S, USP30AS1, AC020916.2, LINC01150, AC068870.2, AC068870.2. 
A

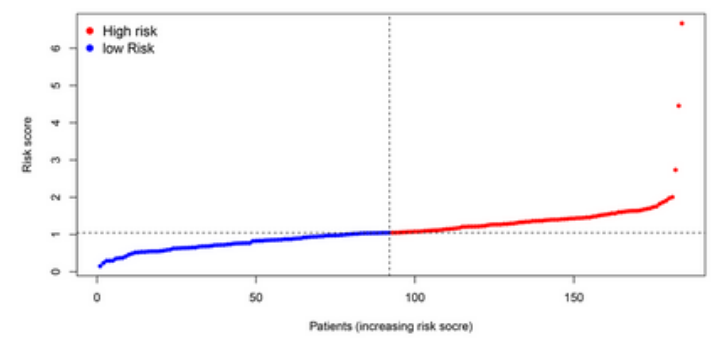

C

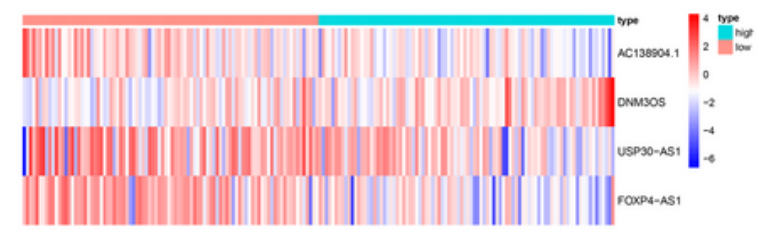

$\mathrm{E}$

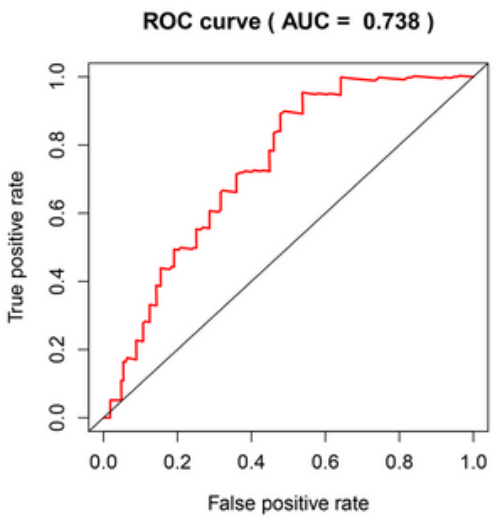

ROC curve $($ AUC $=0.673)$

G

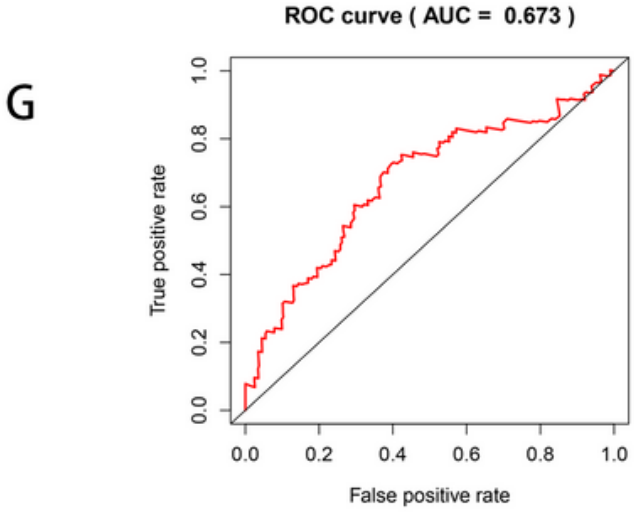

B

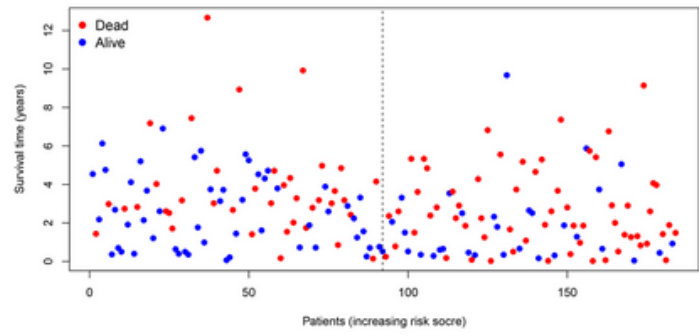

D

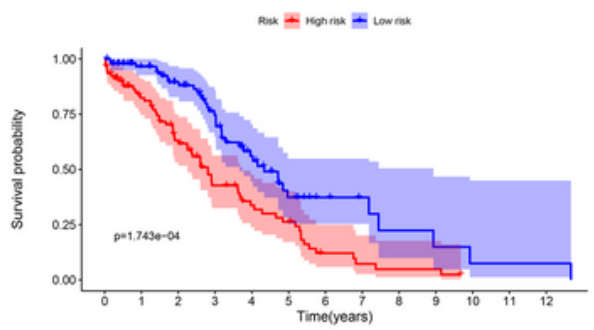

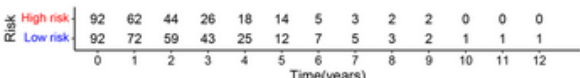

ROC curve $($ AUC $=0.737)$

$\mathrm{F}$

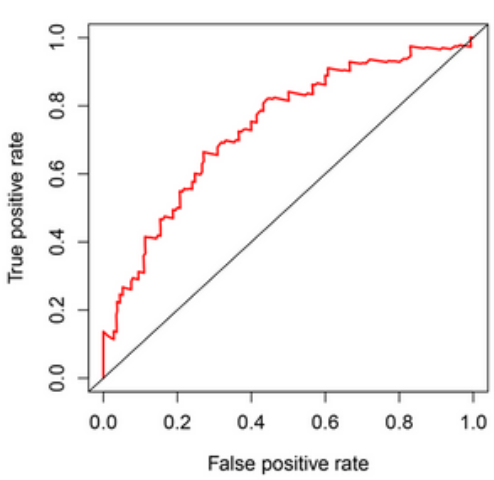

\section{Figure 3}

The predictive power of a novel, four IncRNA prognostic risk score in the primary dataset. (A) Risk score grouping based on prognostic features. (B) OS status scatter plot. (C) Heatmap of four OS-related IncRNAs. (D) Low- and high-risk group Kaplan-Meier curves for OS. (E-G) receiver operating characteristic curves were used to validate the predictive accuracy of prognostic features for 1,2 , and 3 year OS in the primary dataset. 
A

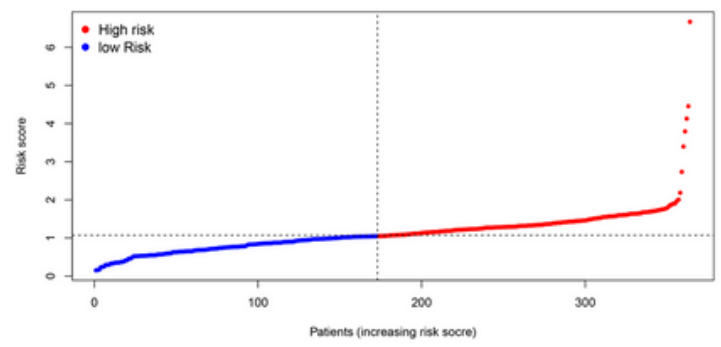

C

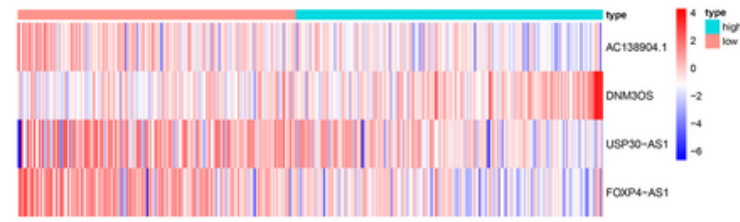

$E$

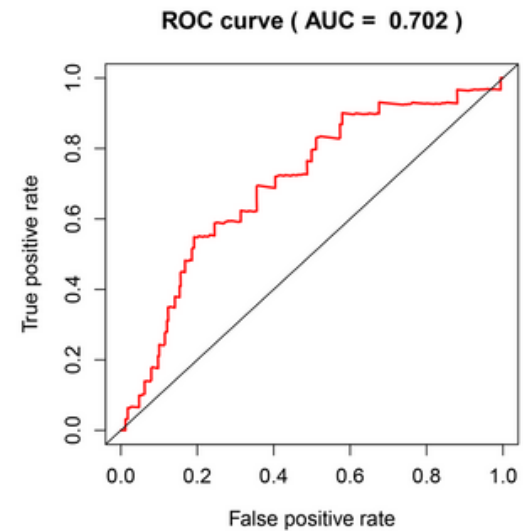

ROC curve ( $A U C=0.632)$

G

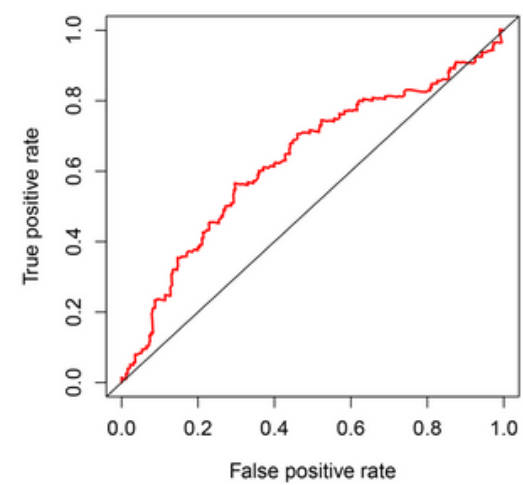

B

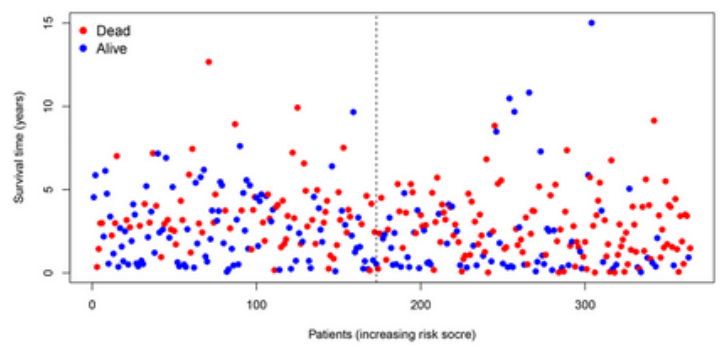

D

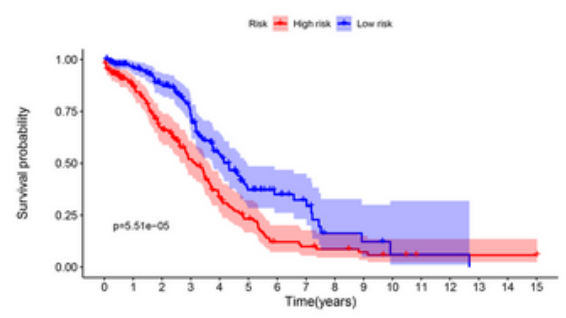

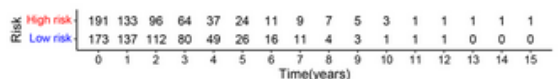

$\mathrm{F}$

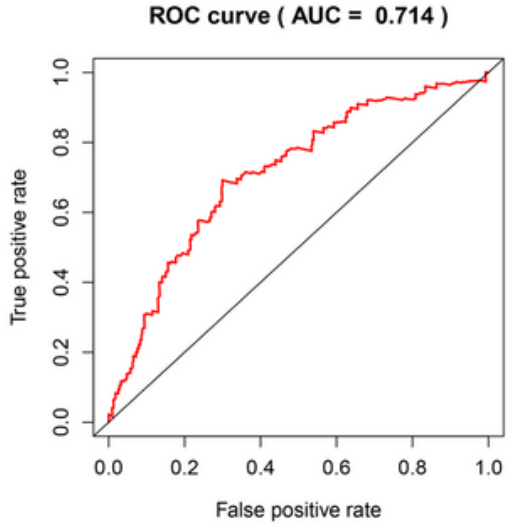

\section{Figure 4}

The predictive power of a four IncRNA prognostic risk score in the entire dataset. (A) Risk score grouping based on prognostic features. (B) OS status scatter plot. (C) Heatmap of four OS-related IncRNAs. (D) Low- and high-risk group Kaplan-Meier curves for OS. (E-G) receiver operating characteristic curves were used to validate the predictive accuracy of prognostic features for 1,2, and 3 year OS in the entire dataset. 
A

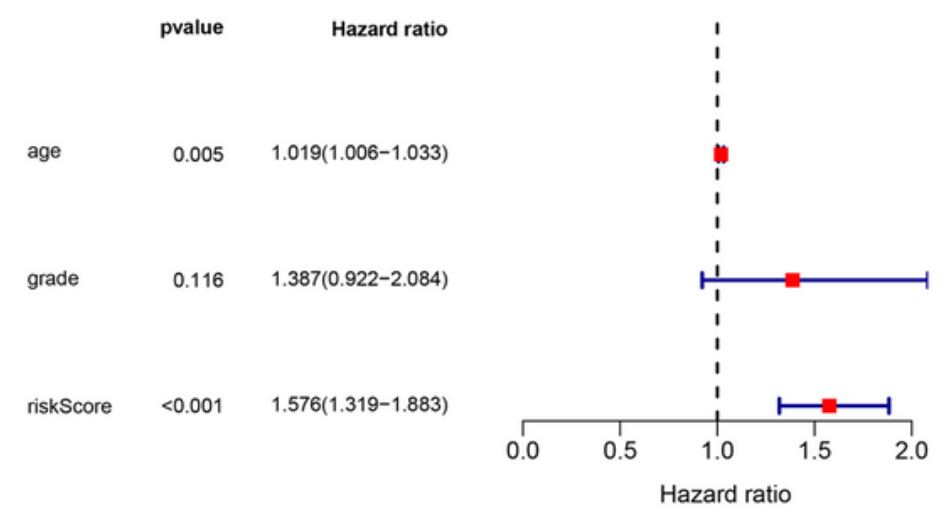

B

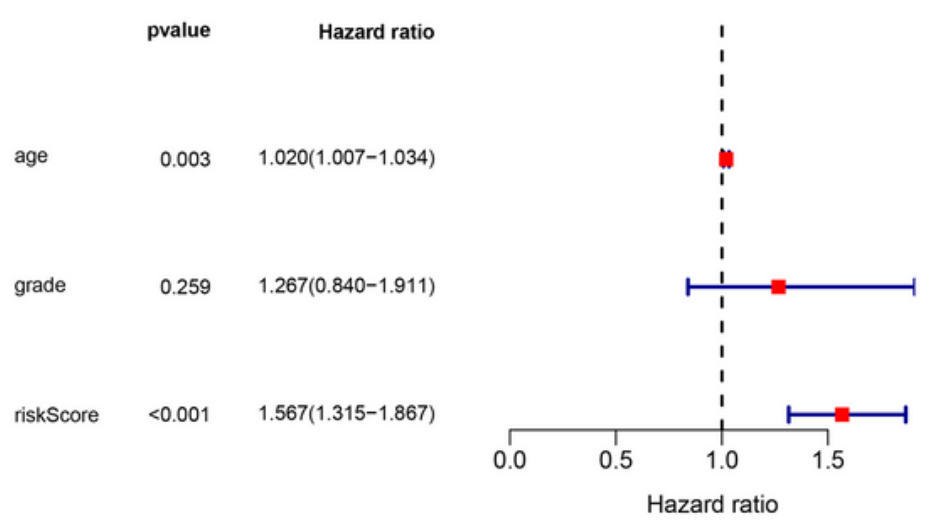

C

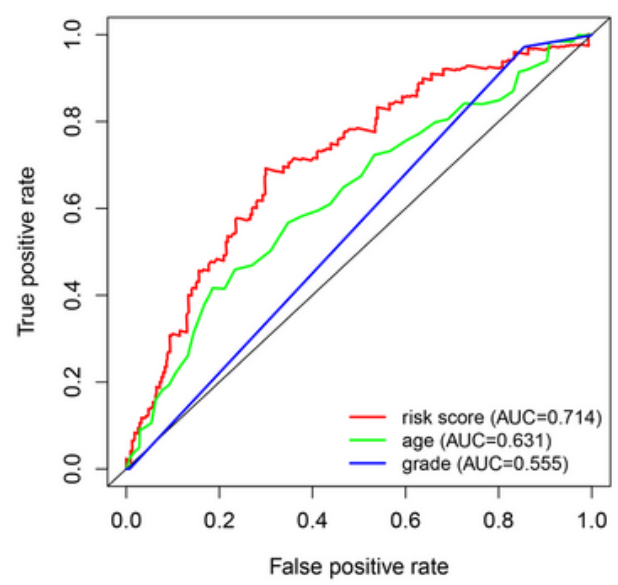

\section{Figure 5}

Estimated prognostic accuracy of the ferroptosis-related IncRNAs prognostic risk score and other clinicopathological variables in $\mathrm{OC}$ patients. (A) Univariate Cox regression analysis showed that age, risk score, and OS significantly associated. (B) Multivariable Cox regression analysis showed that age and the risk score act as independent prognostic indicators for OC patients. (C) receiver operating characteristic curve analysis of the prognostic accuracy of the prognostic risk score, age and grade. 
A

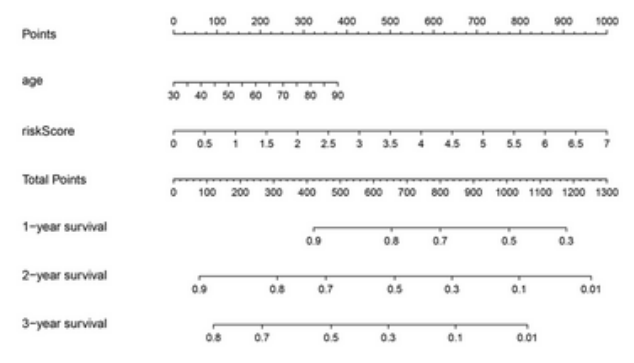

B

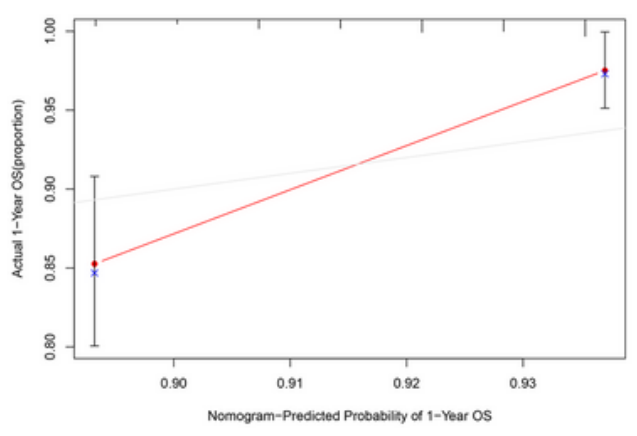

C

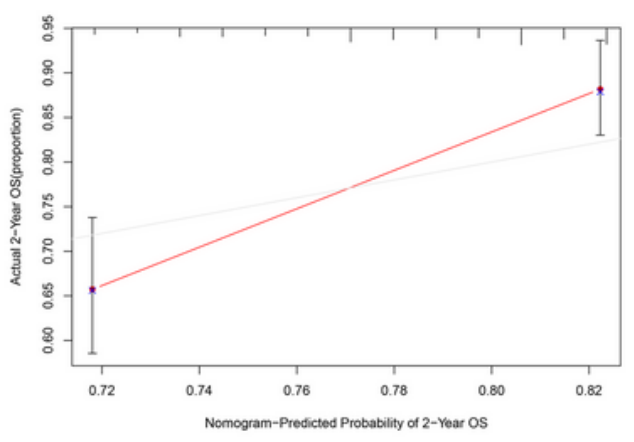

D

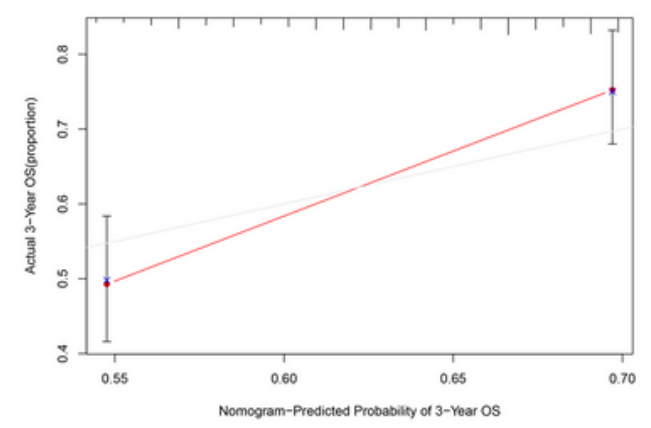

\section{Figure 6}

Construction and validation of prognostic nomograms. (A) Prognostic nomogram based on a fourferroptosis-related IncRNA prognostic risk score and age. (B-D) Calibration curves for the prognosis-based nomograms for high- and low-risk OC patients highlight the small deviation between predicted and actual survival rates. 


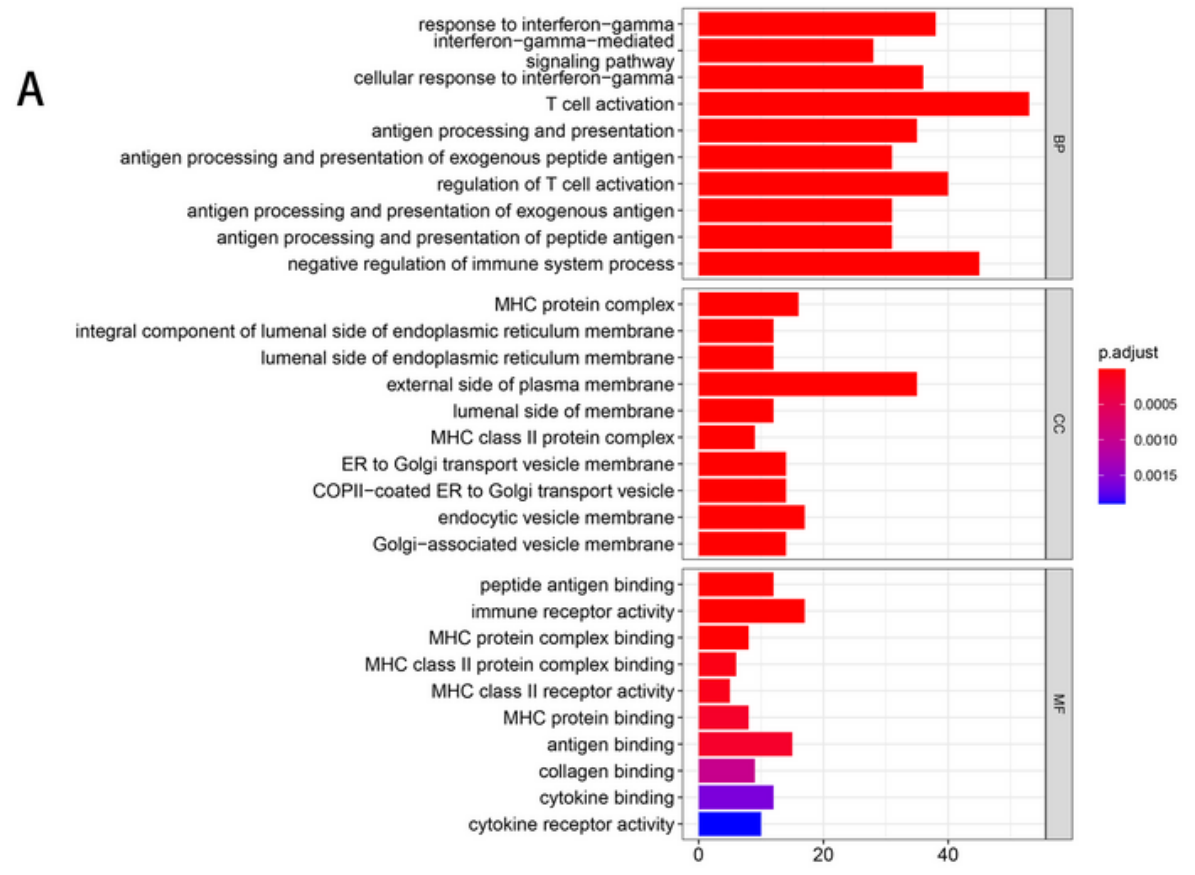

B

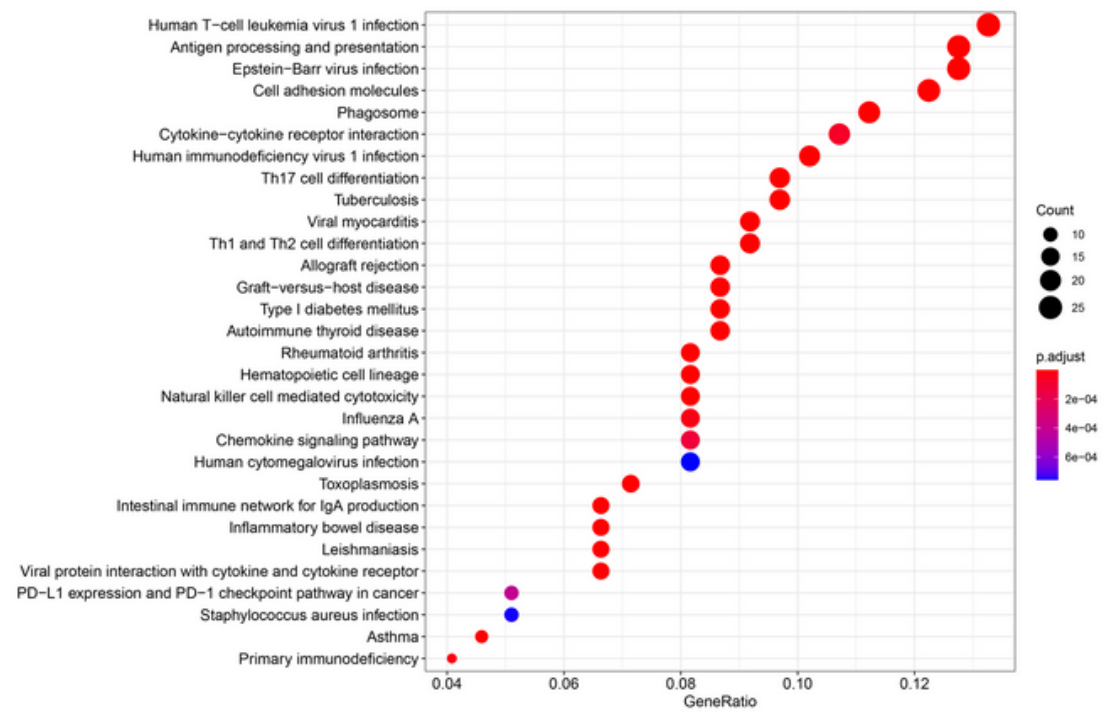

Figure 7

Functional assessment of ferroptosis-related IncRNA mRNA targets. (A) GO enrichment analysis. (B) KEGG enrichment analysis.

\section{Supplementary Files}


This is a list of supplementary files associated with this preprint. Click to download.

- SupplementaryTable1.xls

- SupplementaryTable2.xls

- SupplementaryTable3.xls 